\title{
Biker's Nodule: A Perineal Nodular Induration of the Cyclist
}

\author{
Alakeel Abdullah, Halabi-Tawil Maya, Besseige Henri, Crickx Béatrice, Descamps Vincent \\ Department of Dermatology, Bichat Claude Bernard Hospital, Assistance Publique-Hôpitaux de Paris, Paris, France \\ Email: vincent.descamps@bch.aphp.fr
}

Received October 29, 2011; revised November 30, 2011; accepted December 11, 2011

\begin{abstract}
A case of "biker's nodule" in an 80 year-old cyclist is reported. The "biker's nodule" is caused by repeated microtrauma to the subcutaneous fatty tissue or collageneous tissue on the perineal region resulting in a perineal nodular induration.
\end{abstract}

Keywords: Perineal Nodular Induration; Biker’s Nodule; Hygroma

\section{Introduction}

An 80 year-old patient consulted at our clinic for a large perineal mass that had been growing very slowly over time. The patient had no particular medical history, and there was no family history of a similar anomaly. Of note, he had been cycling for years. Physical examination revealed a soft, non-painful mass inferior to the scrotum (Figures 1 and 2). It had the size of an orange, and was covered by normal skin. There was no lymphadenopathy.

The first evoqued diagnosis was a perineal lipoma. A scrotal ultrasonography was done and revealed a small varicocele and a bilateral vaginal hydrocele. It showed no abnormality regarding the two testicles, as well as no lymphadenopathies. The diagnosis of perineal nodular in-

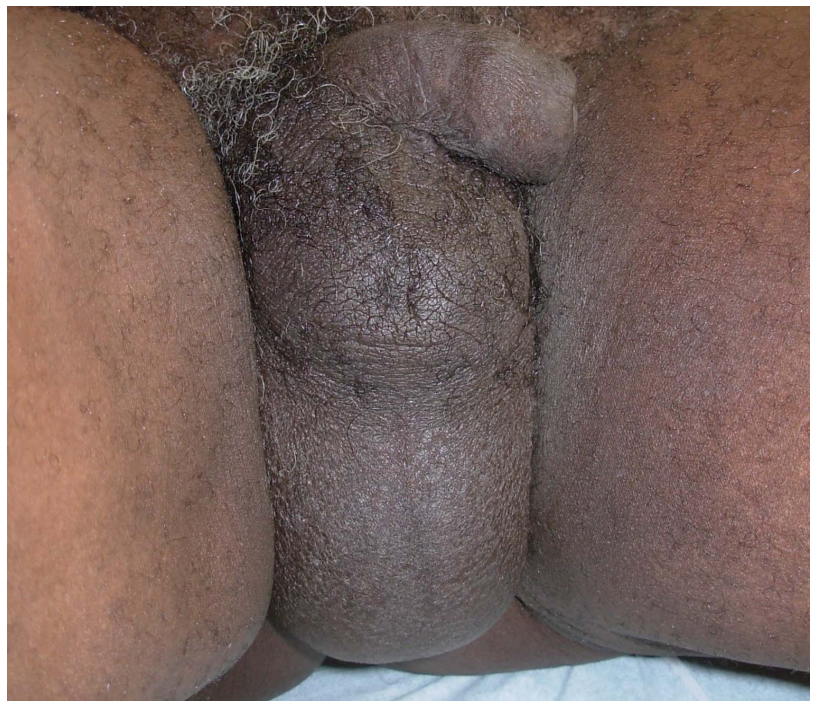

Figure 1. Non-painful mass inferior to the scrotum with normal skin. duration of the cyclist or "biker's nodule” was made after concertation with the urologists. The patient rejected the surgical excision.

\section{Discussion}

Perineal nodular induration of the cyclist, also called "ischiatic hygroma", "accessory testicles", "third testicle"

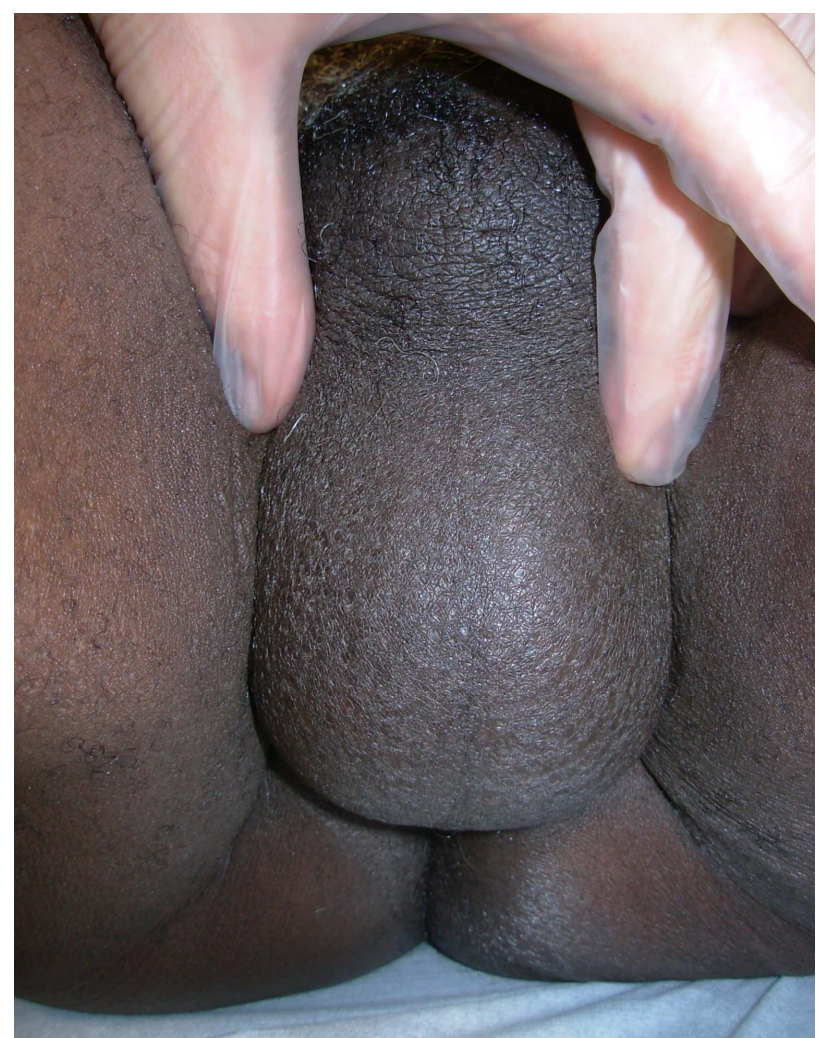

Figure 2. Perineal nodular induration. 
or "biker's nodule”, seem to be relatively well known by European sports medicine specialists as well as professional or amateur cyclists since they are virtually restricted to cyclists [1]. Clinically, it usually presents as two nodules, one on each side of the raphe, although it occasionally presents as a single nodule, which is then called $3^{\text {rd }}$ testicle and is located immediately below the scrotum, close to the ischial tuberosity $[2,3]$.

Differential diagnoses include common minor disorders such as cysts and lipomas, which can be easily recognised by ultrasonography. Biker's nodule should also be differentiated from another, rarer but more serious condition known as aggressive angiomyxoma, which is a variety of myxoid tumor that infiltrate locally and is associated with a high risk of local recurrence after resection, but has no metastatic potential.

It is believed that repeated microtrauma to the subcutaneous fatty tissue or collageneous tissue, caused by pressure or vibration exerted by the bicycle's saddle on the perineal region, lead to collagenous degeneration, myxoid alteration and pseudocyst formation, resulting in biker's nodule [4].

The treatment of these nodules mainly consists of reducing the causative factors, which may lead to regression, but surgical excision is most often needed. Steroid or hyaluronidase injections may be helpful in early le sions and if the patient is a professional cyclist, since surgical exci- sion is a very difficult option in that case.

\section{Conclusion}

Biker's nodule is a rare and benign entity but it represents a genuine handicap for professional cyclists and can contraindicate cycling.

\section{REFERENCES}

[1] N. De Saint Aubain Somerhausen, B. Geurde and Y. Couvreur, "Perineal Nodular Induration: The Third Testicle of the Cyclist: An Under-Recognized Pseudotumour,” Histopathology, Vol. 42, No. 7, 2003, pp. 615616. doi:10.1046/j.1365-2559.2003.01592.x

[2] P. N. Vuong, C. T. Camuzard and M. F. Schoonaert, "Perineal Nodular Indurations (Accesory Testicles) in Cyclists, Fine Needle Aspiration Cytologic and Pathologic Findings in Two Cases,” Acta Cytologica, Vol. 32, No. 1, 1988, pp. 86-90.

[3] R. González-Pérez, L. Carnero, N. Arbide and R. Soloeta, "Perineal Nodular Induration in Cyclists," Actas DermoSifiliograficas, Vol. 100, 2009, pp. 907-922.

[4] P. Kohler, S. Utermann, B. Kahle and W. Hartschuh, "Biker's Nodule-Perineal Nodular Induration of the Cyclist,” Hautarzt, Vol. 51, No. 10, 2000, pp. 763-765. 